\title{
A Case of Cushing's Disease with Hyperglycemia in a Pony
}

\author{
Jun SATO'*, Reeko SATO ${ }^{1}$, Kazumi ITOH ${ }^{2}$, Tsunenori TSUJIMOTO², Etsuko FUJII ${ }^{3}$, \\ Masanobu GORYO ${ }^{3}$ and Yoshihisa NAITO $^{1}$
}

${ }^{1}$ Department of Veterinary Internal Medicine, Faculty of Agriculture, Iwate University, 3-18-8 Ueda, Morioka, Iwate 020-8550, ${ }^{2}$ Morioka Zoological Park, 60-18 Shinjyo aza shimoyagita, Morioka, Iwate 020-0803 and ${ }^{3}$ Department of Veterinary Pathology, Faculty of Agriculture, Iwate University, 3-18-8 Ueda, Morioka, Iwate 020-8550, Japan

A 15-year-old pony mare showed signs of inactivity, dehydration, weight loss, hyperglycemia and glucosuria. After 4 years from the first hospitalization, the pony had the same clinical signs and hirsutism, and died in spite of the treatment. Plasma concentrations of cortisol and insulin in the case had increased to extremely high levels. Necropsy revealed enlargement of the pars intermedia of the pituitary gland and hyperplasia of the adrenal cortex. We concluded that this case was Cushing's disease.

Key words: Cushing's disease, pony
J. Equine Sci. Vol. 10, No. 1 pp. $17-20,1999$
Cushing's disease has been defined as secondary hypercortisolism caused by hypersecretion of ACTH from a pituitary tumor [2, 7] in the horse. There have been some reports on equine Cushing's disease overseas [1, 5, 8, 9, 11]. In Japan, Okada et al. [10] recently reported the first case of equine Cushing's disease, describing a morphological and endocrinological examination of the pituitary and the adrenal gland. There are also many reports of diabetes mellitus associated with functional pituitary adenoma, functional adrenocortical adenoma, pheochromocytoma and chronic pancreatitis in the horse $[5,12]$. In the present report we describe a case of Cushing's disease with hyperglycemia in a pony.

A 15-year-old pony mare showed signs of inactivity, dehydration and weight loss in August 1993. The major laboratory examination findings were hyperglycemia (450 mg/dl), glucosuria (500 mg/dl) and ketonuria (15 $\mathrm{mg} / \mathrm{dl})$. The pony was treated by infusion of Ringer's fluid for 20 days, and recovered without insulin therapy. Detailed examination for hyperglycemia was not performed at that time, and the cause of hyperglycemia was unknown to us. Hematological and biochemical examinations were performed at various times for 4 years (Table 1).

This article was submitted November 9, 1998 and was accepted June 8, 1999.

*corresponding author.
Moderate increases in BUN and plasma glucose concentrations were occasionally observed from September 1993 to April 1997. The pony showed symptom of hirsutism and muscle wasting in July 1997, and then showed symptom of inactivity, anorexia, dehydration, weight loss ( $-35 \mathrm{~kg}$ in a month) and hyperpnea in August 1997. White blood cell counts and many other biochemical parameters such as glucose, total cholesterol, triglyceride, $\gamma$-GTP, AST, $\mathrm{LDH}$ and BUN increased to high levels. Marked increases in plasma insulin and cortisol were observed. Glucosuria $(500 \mathrm{mg} / \mathrm{dl})$, proteinuria $(300 \mathrm{mg} / \mathrm{dl})$ and urinary occult blood $(1 \mathrm{mg} / \mathrm{dl})$ by test strip were observed. There were substances like coagulated blood in the urine. The pony showed clinical signs of fever $\left(41.7^{\circ} \mathrm{C}\right)$, severe hyperpnea and dysstasia, and died in spite of treatment for a week.

At postmortem examination, a well demarcated pituitary tumor measuring $0.8 \mathrm{~cm}$ in diameter was found. Both adrenal glands were extensively enlarged (right $8 \times$ $4.5 \times 1.4 \mathrm{~cm}$, left $8 \times 4.5 \times 3 \mathrm{~cm})$. Nodular hyperplasia in both adrenal cortices was observed. Cysts with a maximum diameter of $1.4 \mathrm{~cm}$ in both renal cortices and a mucous gelatin-like substance in the renal pelvis of the right kidney were observed. Multiple chronic abscesses were present in the lungs.

Portions of the pituitary gland, adrenal glands, kidneys and pancreas were taken for histological examination. 
Table 1. Hematological and biochemical results for the pony from August 1993 to August 1997

\begin{tabular}{lccccccccc}
\hline & Aug. 93 & Sep. 93 & Dec. 93 & Sep. 94 & Dec. 94 & Apr. 95 & Apr. 96 & Apr. 97 & Aug. 97 \\
\hline Red blood cell $\left(10^{4} / \mu \mathrm{l}\right)$ & 753 & 1146 & 1195 & 724 & 570 & 556 & 995 & 695 & 1043 \\
Hematocrit $(\%)$ & 45 & 46 & 31 & 41 & 32 & 46 & 40.5 & 34 & 45 \\
Hemoglobin $(\mathrm{g} / \mathrm{dl})$ & 16.1 & 20.0 & 10.4 & 18.2 & 12.5 & 17.1 & 12.1 & 11.5 & 14.3 \\
White blood cell $(/ \mu \mathrm{l})$ & 9500 & 13100 & 7000 & 9100 & 9300 & 5800 & 6930 & 8910 & 18810 \\
$\quad$ Segment $(\%)$ & 79 & 79 & N.D. & 95 & 62 & 69 & 50 & N.D. & 94 \\
$\quad$ Stab $(\%)$ & 3 & 2 & N.D. & 0 & 0 & 3 & 0 & N.D. & 3 \\
$\quad$ Eosinophil $(\%)$ & 0 & 0 & N.D. & 0 & 1 & 0 & 2 & N.D. & 0 \\
$\quad$ Monocyte $(\%)$ & 1.5 & 0 & N.D. & 0 & 1 & 0 & 0 & N.D. & 1 \\
$\quad$ Lymphocyte $(\%)$ & 16.5 & 19 & N.D. & 5 & 36 & 28 & 48 & N.D. & 2 \\
Plasma total protein $(\mathrm{g} / \mathrm{dl})$ & 6.3 & 7.0 & 6.0 & 5.6 & 6.4 & 5.9 & 5.8 & 6.3 & 8.8 \\
Glucose $(\mathrm{mg} / \mathrm{dl})$ & 450 & 83 & 91 & 160 & 110 & 93 & 87 & 82 & 622 \\
Total cholesterol $(\mathrm{mg} / \mathrm{dl})$ & 141 & 222 & 103 & 153 & 123 & 110 & 107 & 93 & 360 \\
Triglyceride $(\mathrm{mg} / \mathrm{dl})$ & 244 & 290 & 39 & 206 & 89 & 56 & 145 & 55 & 922 \\
Total bilirubin $(\mathrm{mg} / \mathrm{dl})$ & 3.0 & 4.5 & 1.7 & 1.3 & 1.3 & 1.3 & 1.8 & .5 & 3.0 \\
$\gamma$ Glutamyl transpeptidase $(\mathrm{U} / \mathrm{l})$ & 79 & N.D. & 27 & 20 & 26 & 16 & 30 & 47 & 179 \\
Aspartate aminotransferase $(\mathrm{U} / \mathrm{l})$ & 142 & 347 & 167 & 151 & 145 & 205 & 193 & 422 & 820 \\
Alanin aminotransferase $(\mathrm{U} / \mathrm{l})$ & 50 & 35 & 14 & 23 & 13 & 28 & 15 & 10 & 167 \\
Lactate dehydrogenase $(\mathrm{U} / \mathrm{l})$ & 835 & 533 & 570 & 590 & 600 & 826 & 907 & 946 & 1864 \\
Blood urea nitrogen $(\mathrm{mg} / \mathrm{dl})$ & 33.2 & 64.3 & 21.0 & 16.7 & 31.7 & 19.1 & 14.7 & 56.0 & 68.0 \\
Plasma cortisol $(\mu \mathrm{g} / \mathrm{dl})$ & N.D. & N.D. & N.D. & N.D. & N.D. & N.D. & N.D. & N.D. & 21.5 \\
Plasma insulin $(\mu \mathrm{U} / \mathrm{ml})$ & N.D. & N.D. & N.D. & N.D. & N.D. & N.D. & N.D. & N.D. & 116 \\
\hline
\end{tabular}

N.D.: not determined.

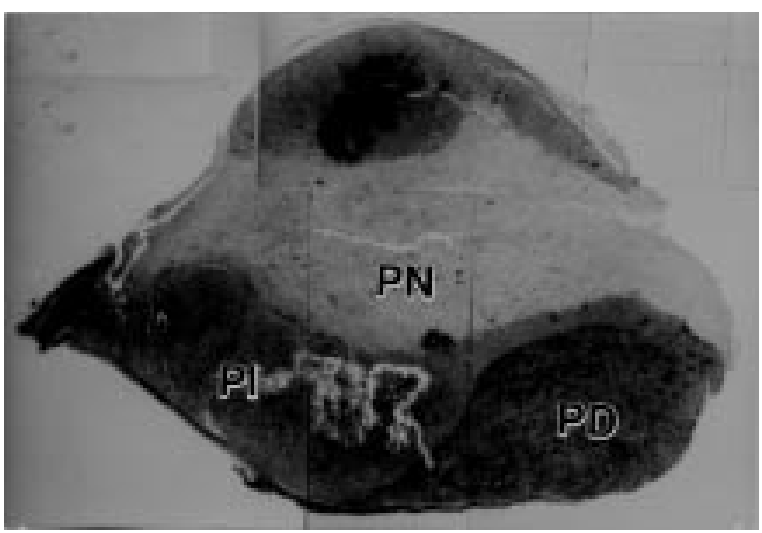

Fig. 1. Pituitary gland in sagittal plane. The pars intermedia (PI) is greatly enlarged and has compressed the pars distalis $(\mathrm{PD})$. (PN: pars nervosa) HE stein $\times 3.8$.

They were fixed in 10\% formaline, embedded in paraffin wax and sectioned at $5 \mu \mathrm{m}$. All tissues were stained with Hematoxylin and Eosin, and renal tissue was stained for the Periodic acid Schiff reaction (PAS). In the pituitary gland the pars intermedia was greatly enlarged and compressed the pars distalis (Fig. 1). Adenoma was observed in the pars intermedia. The tumor cells had round to oval nuclei, sparse chromatin and one to several nucleoli. The cytoplasm was eosinophilic and spindle-

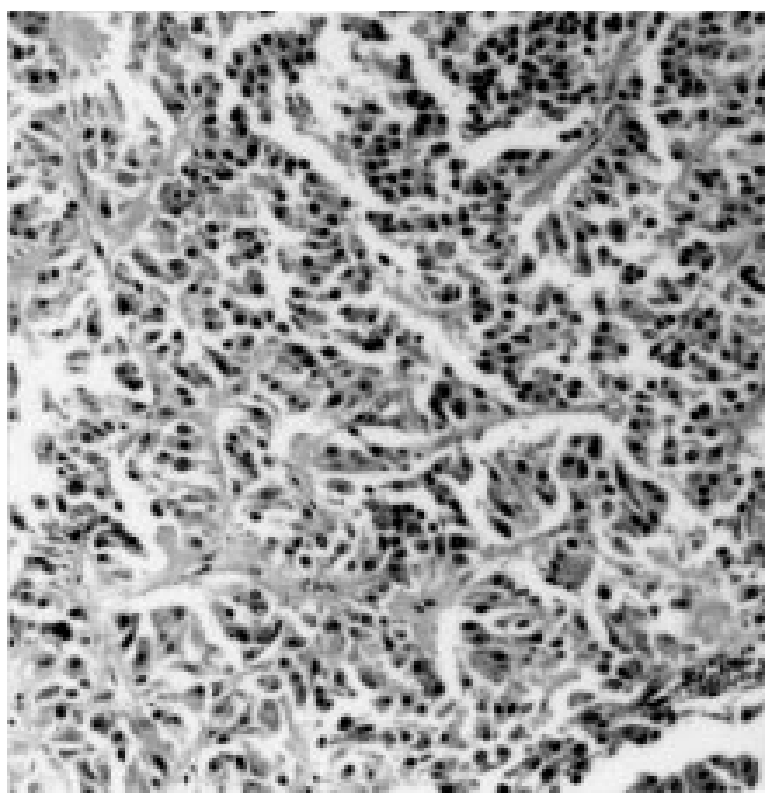

Fig. 2. The tumor cells are spindle-like in shape, and are subdivided by fine septa of connective tissue. HE stein $\times 175$.

like in shape (Fig. 2). Hyperplasia of the cortex was observed in both adrenal glands. Hyperplasia of the zona fasciculata occurred in the right adrenal gland (Fig. 3). 


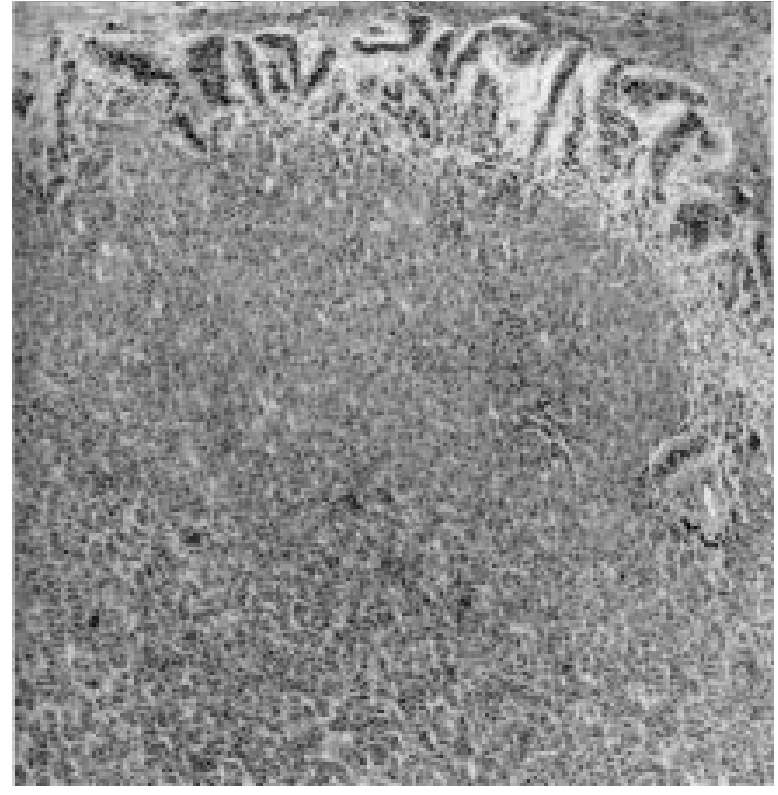

Fig. 3. Hyperplasia of the zona fasciculata in the right adrenal gland. HE stein $\times 35$.

Severe fibrosis and hemorrhage were observed in the interstitium of the adrenal cortex. A vast area of necrosis was observed in the right adrenal gland. A number of the Bowman's capsules and glomeruli showed signs of hyalinization (Fig. 4). Dilated renal tubules and severe interstitial fibrosis were observed in both renal cortices. Severe hyperplasia of glandular cells was observed in the renal pelvis of the right kidney. The mucous substance of the lumen was PAS positive. A nodule of papillotubular adenoma was also seen in the hyperplastic area of the renal pelvis. No significant lesion was observed in the pancreas.

Clinical signs of equine Cushing's disease are generally hirsutism, laminitis, polyuria, polydipsia, hyperhidrosis and muscle wasting $[2,7]$. Previous studies reported that horses with adenomas of the pars intermedia of the pituitary gland showed clinical signs of hirsutism $[9,10$, 12], polyuria, polydipsia, weight loss, polyphagia [9, 12], hyperhidrosis [12], docility [9] and dehydration [10]. In this case hirsutism, muscle wasting and weight loss developed, but other clinical signs of Cushing's disease were obscure.

The plasma cortisol level in this case was very high level $(21.5 \mu \mathrm{g} / \mathrm{dl})$, whereas the plasma cortisol level in a normal horse is reported to be $1.30-2.93 \mu \mathrm{g} / \mathrm{dl}$ [6]. Although the ACTH level was not determined, hypersecretion of ACTH from the enlarged pars intermedia of the pituitary seemed to induce excessive

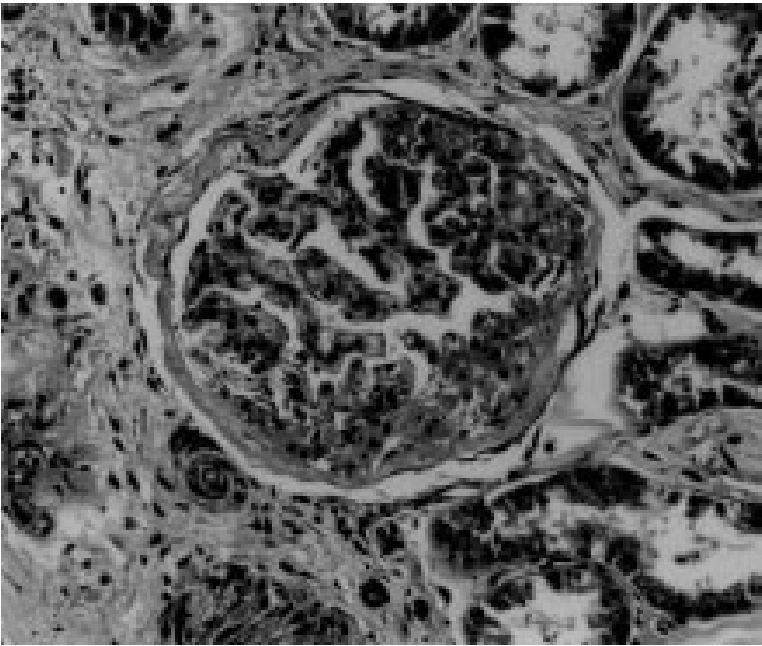

Fig. 4. Bowman's Capsule and glomeruli show signs of hyalinization. HE stein $\times 160$.

secretion of cortisol from the zona fasciculata of the adrenal cortex in this case.

Hyperglycemia occurs commonly in equine Cushing's disease, and is consequent on the insulin insensitivity in hypercortisolaemia [5]. The plasma insulin level in a normal horse is reported to be $24-72 \mu \mathrm{U} / \mathrm{ml}$ [11]. In comparison with the fasting plasma insulin level (10-20 $\mu \mathrm{U} / \mathrm{ml}$ ) of four normal horses, that of this case was very high $(116 \mu \mathrm{U} / \mathrm{ml})$. The insulin concentrations in horses with Cushing's syndrome were reported to be high [3]. Excessive glucocorticoid induces peripheral insulin resistance [13]. Previous studies reported on the raising of resting plasma insulin levels [3,11], failure to reduce hyperglycemia after the administration of exogenous insulin $[3,11]$ and intolerance of intravenous glucose [4] in horses with a high glucocorticoid level. These abnormalities in the metabolism of insulin and glucose were explained by the fact that the chronic excessive glucocorticoid induced a decreased affinity of target cell receptors for insulin [3]. It was thought that the high level of cortisol in this case induced insulin resistance resulting in hyperglycemia and glucosuria.

Dexamethasone suppression test, ACTH stimulation test and insulin tolerance test were necessary for the diagnosis of equine Cushing's disease [2]. Although those tests were not performed, the case was suspected of being Cushing's disease due to the clinical signs of hirsutism, muscle wasting and weight loss, hyperglycemia and increased cortisol. Judging from postmortem findings of the pituitary and the adrenal glands, we concluded that this case was one of Cushing's disease. 


\section{References}

1. Boujon, C.E., Bestetti, G.E., Meier, H.P., Straub, R., Junker, U., and Rossi, G.L. 1993. Equine pituitary adenoma: a functional and morphological study. J. Comp. Pathol. 109: 163-178.

2. Dybdal, N.O. 1996. Endocrine disorders. pp. 14441454. In: Large Animal Internal Medicine, 2nd ed. (Smith, B.P. ed), Mosby-Year Book, Missouri.

3. Field, J.R. and Wolf, C. 1988. Cushing's syndrome in a horse. Equine Vet.J. 20: 301-304.

4. Garcia, M.C. and Beech, J. 1986. Equine intravenous glucose tolerance test: glucose and insulin responses of healthy horses fed grain or hay and of horses with pituitary adenoma. Am.J. Vet. Res. 47: 570-572.

5. Hillyer, M.H., Taylor, F.G.R., Mair, T.S., Murphy, D., Watson, T.D.G. and Love, S. 1992. Diagnosis of hyperadrenocorticism in the horse. Equine Vet. Educ. 4: 131-134.

6. Hodson, N.P., Wright, J.A. and Hunt, J. 1986. The sympatho-adrenal system and plasma level of adrenocorticotoropic hormone, cortisol and catecholamines in equine grass sickness. Vet. Rec. 119: 148-150.

7. Love, S. 1993. Equine Cushing's disease. Br. Vet.J.
149: 139-153.

8. Millington, W.R., Dybdal, N.O., Dawson, R.Jr., Manzini, C., and Mueller, G.P. 1988. Equine Cushing's disease: differential regulation of betaendorphin processing in tumors of the intermediate pituitary. Endocrinology 123: 1598-1604.

9. Moore, J.N., Steiss, J., Nicholson, W.E., and Orth, D.N. 1979. A case of pituitary adrenocorticotropindependent Cushing's syndrome in the horse. Endocrinology 104: 576-582.

10. Okada, T., Yuguchi, K., Kiso, Y., Morikawa, Y., Nambo, Y., and Oikawa, M. 1997. A case of a pony with Cushing's disease. J. Vet. Med. Sci. 59: 707710 .

11. Orth, D.N., Holscher, M.A., Wilson, M.G., Nicholson, W.E., Plue, R.E., and Mont, C.D. 1982. Equine Cushing's disease: plasma Immunoreactive proopiolipomelanocortin peptide and cortisol level basely and in response to diagnostic test. Endocrinology 110: 1430-1441.

12. Staempfli, H.R., Eigenmann, E.J., and Clarke, L.M. 1988. Insulin treatment and development of antiinsulin antibodies in a horse with diabetes mellitus associated with a functional pituitary adenoma. Can. Vet.J. 29: 934-936.

13. Stogdale, L. 1986. Definition of diabetes mellitus. Cornell Vet. 76: 156-174. 